We thank the National Kidney Research Fund for their support of this work.

\section{References}

1 Ellis HA, Peart KM. Azotaemic renal osteodystrophy - a quantitative study on iliac bone. F Clin Pathol 1973;26:83-101.

Kanis JA. Features and pathophysiology of renal bone disease. In: Anderton JL, Parsons FM, Jones DE, eds. Living with renal failure. Lancaster: MTP

Moorhead JF, Tatler GLV, Baillod RA, Varghese Z, Wills MR, Farrow SC Efrects of age, sex, and polycystic disease on progressive bone disease of renal
failure. Br Med $f 1974 ;$ iv:557-60.

4 Palma FJM, Ellis HA, Cook DB, et al. Osteomalacia in patients with chronic renal failure before dialysis or transplantation. $Q \mathcal{J}$ Med 1983;52:332-48.

5 Potter DE, Wilson CJ, Ozonof MB. Hyperparathyroid bone disease in children undergoing long-term hemodialysis: treatment with vitamin $D$. $\mathcal{F}$ Pediatr $1974 ; 85: 60-6$.

6 Broyer $M$. Chronic renal failure. In: Royer $P$, Habib R, Mathieu $H$, Broyer $M$, eds. Pediatric nephrology. Philadelphia: W B Saunders, 1974:358-94.

7 Meema HE, Oreopoulos DG, Uldall PR. The influence of age and sex on bone resorption of secondary hyperparathyroidism. Calcif Tissue Int 1984;36:25-30. Intern Med 1969;124:312-21.

9 Kanis JA, Cundy T, Earnshaw $M$, et al. Treatment of renal bone disease with $1 \alpha$-hydroxylated derivatives of vitamin $D_{3}$. Clinical, biochemical, radiographic and histological responses. $Q \mathcal{F}$ Med 1979;48:289-322.

10 Kanis JA, Earnshaw M, Heynen G, et al. Changes in histologic and biochemical indexes of bone turnover after bilateral nephrectomy in patients on hemodialysis. Evidence for a possible role of endogenous calcitonin. $N$ Engl f Med 1977;296:1073-9.

11 Woods CG, Morgan DB, Patterson CR, Grossman HH. Measurement of osteoid in bone biopsy. 7 Pathol Bacterio

SE. The analysis of cross-classified categorical data. Cambridge, Massachusetts: MIT Press, 1979.

13 Armitage P. Statistical methods in medical research. Oxford: Blackwell, 1971. Bone histology in incipient and advanced renal failure. Kidney Int 1976;9:

15 Ott SM, Maloney NA, Coburn JW, Alfrey AC, Sherrard DJ. The prevalence of bone aluminium deposition in renal osteodystrophy and its relation to the response of calcitriol therapy. $N$ Engl $f$ Med 1982;307:709-13.

16 Bordier PJ, Marie PJ, Arnaud CD. Evolution of renal osteodystrophy : correlation of bone histomorphometry and serum mineral and immunoreactive parathyroid hormone levels before and after treatment with calcium
25 -hydroxycholecalciferol. Kidney Int 1975;7,suppl 2:S 102-12.

17 Parfitt AM. Clinical and radiographic manifestations of renal osteodystrophy. In: David DS, ed. Calcium metabolism in renal failure and nephrolithiasis. New York: J Wiley, 1977:145-97.
18 Clark S. Longitudinal growth studies in normal and scoliotic children. In: Zorab PA, ed. Scoliosis: proceedings of the 5th symposium. London: Academic

19 Nordin BEC. In: Nordin BEC, ed. Calcium, phosphate and magnesivon metabolism. Edinburgh: Churchill Livingstone, 1976:1-35. effect of sexugl D. Plasma concentrations of vitamin D metabolites in puberty: Metab 1982;55:94-101

21 Mawer EB, Backhouse J, Taylor CM, Lumb GA, Stanbury SW. Failure of formation of 1,25 -dihydroxycholecalciferol in chronic renal insufficiency. Lancet 1973; i:626-8.

22 Chesney RW, Moorthy AV, Eisman JA, Jax DK, Mazess RB, Deluca HF. Increased growth after long-term oral $1 \alpha, 25$-vitamin $D_{2}$ in childhood renal 23 Masteodystrophy. N Engl I Med 1978;288:238-42. 24 Kurokawa K, Torikai S, Wang MS, Klein KL, Kawashima H. Metabolic heterogeneity of the nephron. Mineral and Electrolyte Metabolism 1982; 7:225-36.

25 Brenner RJ, Spring DB, Sebastian A, et al. Incidence of radiographically evident bone disease, nephrocalcinosis and nephrolithiasis in various types of renal tubular acidosis. N Engl f Med 1982;307:217-21.

26 Horsman A. Bone mass. In: Nordin BEC, ed. Calcium, phosphate and magnesium metabolism. Edinburgh: Churchill Livingstone, 1976:357-404.

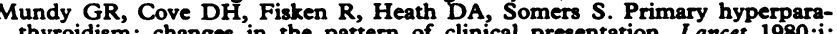
thyroidis

28 Schalch DS, Gonzalez-Barcera D, Kastin AJ, et al. Plasma gonadotrophins after administration of LF-releasing hormone in patients with renal or hepatic failure. $\mathcal{F}$ Clin Endocrinol Metab 1975;41:921-5.

29 Holdsworth S, Atkins RC, DeKretzer DM. The pituitary-testicular axis in men with chronic renal failure. N Engl $\mathcal{F}$ Med 1977;296:1245-9.

30 Eastwood JB, Bordier PJ, Clarkson EM, TunChot S, DeWardener HE. Vitamin $D$ deficiency in the osteomalacia of chronic renal failure. Lancet 1976;ii:

31 Cochran M, Bulusu L, Horsman A, Stasiak L, Nordin BEC. Hypocalcaemia and bone disease in renal failure. Nephron 1973;10:113-40.

33 Cundy T, Kanis JA, Heynen G, et al. Failure to heal vitamin D deficiency rickets with conventional doses of 1,25-dihydroxyvitamin $\mathrm{D}_{3}$. Br Med $f$ $1982 ; 284: 883-5$.

34 Memmos DE, Eastwood JB, Talner LB, et al. Double blind trial of 1,25dihydroxyvitamin $D_{3}$ versus placebo in asymptomatic hyperparathyroidism in patients receiving maintenance haemodialysis. Br Med $\mathcal{F} 1981 ; 282: 1919-24$.
Naik RB, Cundy T, Robinson BHB, Russell RGG, Kanis JA. Effects of vitamin D metabolites and analogues on renal function. Nephron $1981 ; 28: 17-25$.
maik 36 Christiansen C, Rodbro P, Christensen MS, Hartnack B, Transbol I. Deterioradihydroxycholecalciferol. Lancet 1978;ii:700-3.

(Accepted 19 October 1984)

\title{
A prospective randomised controlled clinical trial comparing somatostatin and vasopressin in controlling acute variceal haemorrhage
}

\author{
S A JENKINS, J N BAXTER, W CORBETT, P DEVITT, J WARE, R SHIELDS
}

\begin{abstract}
Twenty two patients were entered into a randomised controlled clinical trial comparing the efficacy of somatostatin and vasopressin in controlling acute variceal haemorrhage. Somatostatin was significantly more successful in controlling acute variceal haemorrhage than vasopressin $(p=0.003)$. Furthermore, no complications were observed during treatment with somatostatin.
\end{abstract}

\footnotetext{
University Department of Surgery, Royal Liverpool Hospital, Liverpool L69 3BX

S A JENKINS, PHD, senior research assistant

J N BAXTER, MB, FRACS, lecturer

W CORBETT, MB, FRCS, lecturer

P DEVITT, MS, FRCs, lecturer

J WARE, MA, FRCs, senior lecturer

R SHIELDS, MD, FRCS, head of department and professor of surgery

Correspondence to: Professor R Shields.
}

\section{Introduction}

The main objective of vasoactive drug treatment of portal hypertension is to control variceal haemorrhage until definitive treatment can be undertaken. Although vasopressin has been used for several years for the emergency control of bleeding oesophageal varices, ${ }^{1}$ it is successful in only about half of all patients. ${ }^{2}$ Moreover, treatment with vasopressin may have undesirable side effects such as coronary vasoconstriction, pulmonary oedema, and abdominal colic. ${ }^{3}$

Somatostatin, first isolated from the hypothalmus in 1972,4 is widely distributed throughout the body, particularly high concentrations being found in the central nervous system, gastrointestinal tract, and pancreas. In addition to inhibiting the release of many gastrointestinal hormones, ${ }^{3-7}$ somatostatin is also a potent inhibitor of gastric and pancreatic secretions. ${ }^{80}$ Furthermore, studies of the effects of somatostatin on hepatic haemodynamics in animals and on wedged hepatic venous pressure in man have suggested that somatostatin may be effective in controlling acute variceal haemorrhage. ${ }^{10} 11$ The aim of this study was to compare the efficacy of somatostatin and vasopressin in controlling acute variceal haemorrhage in a prospective randomised controlled clinical trial. 


\section{Methods}

We studied patients with appreciable variceal haemorrhage as defined by: either systemic disturbance (pulse rate greater than 100 beats/minute, systolic blood pressure less than $100 \mathrm{~mm} \mathrm{Hg}$ ) for two consecutive hours necessitating blood transfusion; or necessity to transfuse two units of blood in 24 hours to maintain vital signs. Bleeding varices were confirmed by endoscopy as the source of haemorrhage in all patients.

Twenty two patients, satisfying the entry criteria, were randomly allocated (using sealed envelopes) to receive intravenously either vasopressin (argipressin; Ferring Pharmaceutical Company) or somatostatin (Serono Laboratories, UK). The cause of portal hypertension, grading of hepatic function according to Child's criteria, ${ }^{12}$ age, sex, and ratio of index to interval episodes of bleeding were similar in the two groups (table I). An index episode of bleeding was defined as the first variceal haemorrhage and interval episodes as all subsequent haemorrhages while the patient was undergoing maintenance sclerotherapy.

TABLE I-Clinical features of patients with acute variceal haemorrhage receiving either vasopressin or somatostatin

\begin{tabular}{lcc}
\hline & $\begin{array}{c}\text { Vasopressin } \\
(\mathbf{n}=12)\end{array}$ & $\begin{array}{c}\text { Somatostatin } \\
(\mathbf{n}=10)\end{array}$ \\
\hline $\begin{array}{l}\text { No with portal hypertension due to: } \\
\text { Cirthosis }\end{array}$ & & \\
Alcohol related & 6 & 5 \\
$\quad$ Cryptogenic & 3 & 3 \\
$\quad$ Primary biliary cirrhosis & 1 & 0 \\
$\quad$ Parcoidosis & 1 & 1 \\
$\quad$ Paroxysmal nocturnal haemoglobinuria & 1 & 1 \\
No wrahepatic block & 1 & 2 \\
A & 2 & 2 \\
B & 4 & 6 \\
C (yild's classification: & 6 & $55 \cdot 8(5 \cdot 0)$ \\
Meears): & $51 \cdot 5(2 \cdot 9)$ & $39-72$ \\
Range & $30-73$ & 6 \\
No of men & 6 & 6 \\
No of episodes of bleeding: & 8 & 4 \\
Index & 4 & \\
Interval & 4 & \\
\hline
\end{tabular}

Patients selected to receive vasopressin were infused at a rate of $0.4 \mathrm{U} / \mathrm{min}$ for six hours. If bleeding stopped the rate of vasopressin infusion was decreased to $0.2 \mathrm{U} / \mathrm{min}$ for the following six hours, then decreased to $0.1 \mathrm{U} / \mathrm{min}$ for a further six hours, and finally stopped if no further bleeding occurred. Patients allocated to receive somatostatin received a bolus dose of $250 \mu \mathrm{g}$ followed by a constant infusion of $250^{\circ} \mu \mathrm{g} / \mathrm{h}$ for 24 hours. Twelve patients received vasopressin and 10 somatostatin. In 18 of the 22 patients vasopressin or somatostatin was used as a first line treatment. In the four remaining patients the varices had been injected on admission as an initial treatment but, because of continued bleeding, they were randomised to receive one or other drug (one vasopressin and three somatostatin).

Successful control of variceal haemorrhage was defined as the stopping of bleeding as evidenced ty the absence of fresh blood in the nasogastric aspirate, stable packed cell volume, or absence of other overt signs of continued bleeding during the 18-24 hours of administration of the vasoactive drug. If haemorrhage was not controlled by the vasoactive drug balloon tamponade of the oesophagus was undertaken using either a Minnesota or a Sengstaken Blakemore tube.

\section{Results}

\section{SOMATOSTATIN}

The variceal haemorrhage was successfully controlled in all 10 patients receiving somatostatin (fig 1). Seven of these patients were subsequently treated with injection sclerotherapy (one to three days later) without any further episodes of bleeding. The three others, however, rebled before definitive treatment could be undertaken.

One of the patients who rebled had been randomised to receive somatostatin after a massive haematemesis following emergency sclerotherapy. The haemorrhage was successfully controlled by infusion of somatostatin, but he rebled on two further occasions after the infusion of somatostatin had been stopped. In both cases infusion of somatostatin was again successful in controlling the variceal bleeding. He subsequently underwent successful oesophageal tran- section using a stapling technique. Another of the three to rebleed refused injection sclerotherapy after initial control of her variceal haemorrhage by somatostatin. She experienced four further appreciable episodes of bleeding in the three weeks after her initial episode, all of which were controlled successfully by a 24 hour infusion of somatostatin. She eventually died from multiple organ failure. The third patient to rebleed did so after initial emergency injection sclerotherapy for acute variceal haemorrhage. The bleeding was successfully controlled by the administration of somatostatin but she subsequently sustained further massive variceal haemorrhage, which was again controlled by somatostatin administration. She underwent oesophageal transection under somatostatin cover but subsequently died from a cardiac arrest in the intensive care unit. I should be pointed out that she had had a cardiac arrest three hours after admission with the initial episode of bleeding.

No complications were observed in any of the 10 patients during infusion of somatostatin.

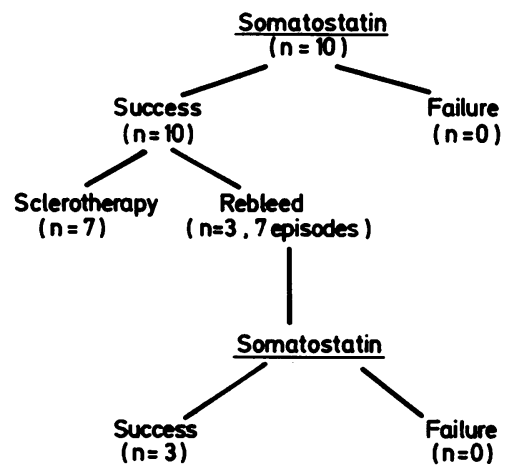

FIG 1-Outcome of treatment with somatostatin in patients with acute variceal haemorrhage.

\section{VASOPRESSIN}

Variceal haemorrhage was successfully controlled by vasopressin in four of the 12 patients (one with Child's grade $A$ hepatic function, two with Child's grade B, and one with Child's grade C), but treatment was unsuccessful in the remaining eight (fig 2 ). In two patients

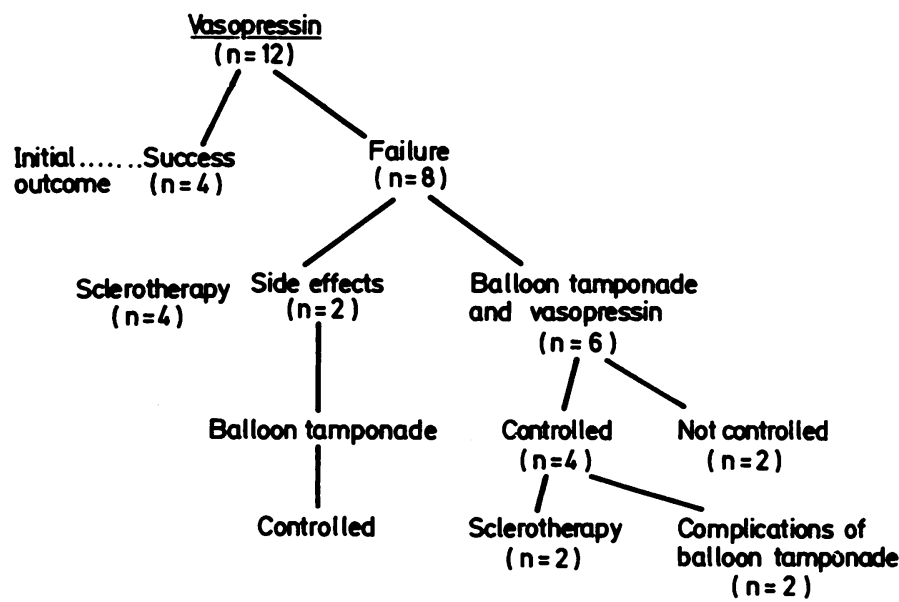

FIG 2 -Outcome of treatment with vasopressin in patients with acute variceal haemorrhage.

administration of vasopressin had to be stopped despite continued active bleeding from the varices because of undesirable side effects (pulmonary oedema in one, chest pain and abdominal colic in the other). Haemorrhage was eventually controlled in these two patients by balloon tamponade.

Balloon tamponade was carried out in the six remaining patients in whom vasopressin failed to control the variceal haemorrhage. In four the variceal haemorrhage was eventually controlled by the 
combination of balloon tamponade and vasopressin, but two of these patients died from direct complications of balloon tamponade (inhalation in one case, oesophageal ulceration and perforation in the other). In the two remaining patients the variceal haemorrhage was not controlled by vasopressin and balloon tamponade. One of these two underwent emergency oesophageal transection but died of liver failure one week later. The other died of a combination of hypovolaemic shock and liver failure before any further treatment could be undertaken.

\section{COMPARISON}

Analysis of the results by Fisher's exact test (table II) showed that somatostatin was successful in a significantly greater number of patients than vasopressin in controlling acute variceal haemorrhage $(p=0.003)$. When the number of episodes of bleeding controlled by somatostatin (17) was compared with the number controlled by vasopressin (four) the difference between the treatments was of even greater significance $(p=0.0002)$.

TABLE II-Results of vasopressin and somatostatin treatment in controlling acute variceal haemorrhage. Figures indicate numbers of patients in whom treatment was successful or unsuccessful with numbers of episodes of bleeding in parentheses

\begin{tabular}{lcc}
\hline & Successful & Not successful \\
\hline Vasopressin $(n=12)$ & 4 & 8 \\
Somatostatin $(n=10)$ & $10(17)$ & 0 \\
\hline
\end{tabular}

$p=0.003$ (0.0002), Fisher's exact test.

\section{Discussion}

The results of this randomised controlled clinical trial suggest that somatostatin is more successful than vasopressin in controlling acute variceal haemorrhage when success is defined as the stopping of bleeding during the administration of the vasoactive drug. Moreover, no complications were observed in those patients who received somatostatin. Although we initially intended to randomise 30 patients to receive either somatostatin or vasopressin, an adverse report ${ }^{13}$ prompted us to perform a preliminary analysis of our data. The highly significant result obtained $(p=0.003)$ in the first 22 patients clearly indicated that the trial should be stopped.

This paper describes the first full report of a randomised clinical trial comparing the efficacy of somatostatin and vasopressin in controlling acute variceal haemorrhage. These results agree with two previous reports, one of which is anecdotal, ${ }^{11}$ the other reported in abstract form only. ${ }^{14}$ Raptis and Zoupas, however, in a study of only five patients found that somatostatin had no beneficial effect in the control of acute variceal haemorrhage. ${ }^{15}$ The reason for the difference in results is difficult to explain. In our experience, success with the administration of somatostatin demands scrupulous attention to detail. The bolus injection must be given after the infusion has been started, and there must be no delay in changing infusion bags. Although Raptis and Zoupas gave a bolus injection followed by a constant infusion for up to 74 hours, they do not give any precise details of their methods of administration or any indication of the precautions they took to ensure that the circulating concentrations of the hormone did not fall to below that required to exert a therapeutic effect. ${ }^{15}$ Furthermore, their failure to show a fall in portal pressure after administration of somatostatin at operation is contrary to observations in cirrhotic rats ${ }^{16}$ and cirrhotic patients, ${ }^{17}$ using roughly the same dose of somatostatin. Their failure to show a beneficial effect of somatostatin in the management of acute variceal haemorrhage may have been related to the method of administration.

Somatostatin has been shown to reduce splanchnic blood flow in experimental animals ${ }^{16} 18$ and in man. ${ }^{11}$ On the basis of these initial studies and the observation that somatostatin lowers wedged hepatic venous pressure in patients with cirrhosis the hormone was suggested to be of possible value in the management of patients presenting with acute variceal haemorrhage. ${ }^{11}$ Reports on the effects of somatostatin on hepatic haemodynamics in cirrhosis have, however, been contradictory. Thus an infusion of somatostatin $(1 \mu \mathrm{g} / \mathrm{kg}$ body weight $/ \mathrm{min}$ ) has been reported to reduce wedged hepatic venous pressure in man. ${ }^{11}$ Similarly, Bosch et al observed that an injection $(1 \mu \mathrm{g} / \mathrm{kg}$ body weight) or an infusion $(7.5 \mu \mathrm{g} / \mathrm{min})$ of somatostatin significantly decreased both wedged hepatic venous pressure and estimated liver blood flow in cirrhotic patients. ${ }^{17}$ In contrast, Sonnenberg et al reported that an infusion of somatostatin $250 \mu \mathrm{g} / \mathrm{h}$ had no effect on wedged hepatic venous pressure or liver blood flow in cirrhotic patients. ${ }^{19}$ The rate of infusion of somatostatin used by Sonnenberg et al $(3.0 \mu \mathrm{g} / \mathrm{kg}$ body weight $/ \mathrm{h})$ was lower than that used in other clinical studies and roughly midway between the rates of infusion of the hormone that either have had no effect or have significantly lowered portal pressure in cirrhotic rats. ${ }^{16}$ Furthermore, we have previously shown that in cirrhotic rats the beneficial effects of an infusion of somatostatin on hepatic haemodynamics are enhanced by prior bolus administration of the hormone. ${ }^{16}$ It therefore seems likely that the conflicting reports on the effects of somatostatin on hepatic haemodynamics in cirrhotic patients may be related to the amount given and the mode of administration.

The precise mode of action of somatostatin has not yet been established. The rapidity of onset of its effects on hepatic haemodynamics in experimental animals and in man suggests that the peptide acts directly on the smooth muscle of the splanchnic blood vessels. ${ }^{10}$

Although bleeding stopped during the infusion of somatostatin in all 10 patients, three of the patients rebled before definitive treatment (either the first injection of sclerosant into the varices or oesophageal transection) could be implemented. These episodes of rebleeding were, however, controlled with further infusions of somatostatin, suggesting that a more prolonged infusion of the hormone may be necessary to reduce further the risk of haemorrhage before definitive treatment is carried out. Prolonged use of somatostatin alone may therefore avoid the use of balloon tamponade with all its recognised risks such as oesophagitis, rupture of oesophagus, aspiration pneumonia, and airway obstruction. The $25 \%$ mortality directly attributable to balloon tamponade in this study is similar to that previously reported. ${ }^{20}$

In addition, somatostatin has several other potential advantages over vasopressin in the management of bleeding oesophageal varices. Firstly, as somatostatin has been shown to stop bleeding from peptic ulcer in about $80 \%$ of patients presenting for treatment ${ }^{21}$ the hormone will have the additional benefit of controlling haemorrhage from other sources when they coexist with oesophageal varices. Secondly, somatostatin has been shown to be effective in controlling haemorrhage from ulcerative oesophagitis, a condition that sometimes accompanies bleeding oesophageal varices. ${ }^{22}$ Finally, somatostatin, by inhibiting gastric acid secretion, ${ }^{8}$ may promote healing by preventing clot dissolution.

In conclusion, somatostatin would appear to be more effective than vasopressin in controlling acute variceal haemorrhage. Furthermore, in both the present study and studies by other workers $^{21}$ administration of somatostatin has appeared to be free from the complications observed during administration of vasopressin. It therefore appears that somatostatin is an effective stopgap measure, giving time for patients' conditions to improve and diagnostic measures to be undertaken.

We thank Serono Laboratories UK Ltd for the gift of somatostatin and for supporting the clinical trial; the junior medical and nursing staff of the professional surgical unit, Royal Liverpool Hospital, who helped with the care of the patients; and $\mathrm{Mr} \mathrm{K}$ Tweedie and Mr C West for statistical advice. 
ADDENDUM-Since this paper was accepted for publication a report of a prospective randomised clinical trial comparing the effects of somatostatin and vasopressin in the control of acute variceal haemorrhage has been published (Kravetz D, Bosch J, Teres J, Bruix J, Rimola A, Rodes J. Comparison of intravenous somatostatin and vasopressin infusion in the treatment of acute variceal haemorrhage. Hepatology 1984;4:442-6). There was no difference in the effectiveness of somatostatin and vasopressin in controlling variceal haemorrhage, but administration of somatostatin was associated with fewer complications. The two trials are not, however, strictly comparable because of differences, to which we have drawn attention (Hepatology, in press), in the mode of administration of somatostatin and vasopressin.

\section{References}

1 Kehne JH, Hughes FA, Gompertz ML. The use of pituitrin in the control of esophageal varices: an experimental study and report of two cases. Surgery

2 Conn HO, Dalessio DJ. Multiple infusions of posterior pituitary extract in the treatment of bleeding oesophageal varices. Ann Intern Med 1962;57:804-9. hon WC, Widrich $W$, Ansell $\mathrm{JE}$, et al. Control of bleeding varices by

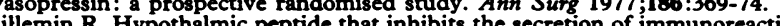
pituitary owth hormone. Science 1973;179:77-9.

Wahren J, Felig P. Influence of somatostatin on carbohydrate disposal and absorption in diabetes mellitus. Lancet $1976 ;$ ii :1213-6.

Bloom SR. Somatostatin and the gut. Gastroenterology 1978;75:145-7.

Bloom SR, Mortimer Ch, Thorner MO, et al. Inhibition of gastrin and gastric acid secretion by growth hormone release-inhibiting hormone. Lancet 1974;
8 Gomez-Pan A, Reed JD, Albinus M, et al. Direct inhibition of gastric acid and pepsin secretion by growth hormone release-inhibiting hormone in the cat.

9 Raptis S, Schlegel W, Lehmann E, et al. Effects of somatostatin on the exocrine pancreas and the release of duodenal hormones. Metabolism 1978;27(suppl 1):

0 Samnegard $\mathrm{H}$, Thulin $\mathrm{L}$, Andreen $\mathrm{M}$, et al. Circulatory effects of somatostatin on anaesthetised dogs. Acta Chir Scand 1979;145:209-12

11 Tyden G, Samnegard $H$, Thulin $L$, et al. Treatment of bleeding oesophageal varices with somatostatin. $N$ Engl $f$ Med 1978;299:1466-7.

12 Child CG, Turcotte JG. Surgery and portal hypertension. In: Child CG, Dunphy JE, eds. Major problems in clinical surgery: the liver and portal hypertension. Vol 1. Philadelphia: WB Saunders, 1964:1-85.

13 Anonymous. Bleeding oesophageal varices [Editorial]. Lancet 1984;i:139-41.

Basso N, Bagarani M, Quondamcarlo C, et al. Effective control of variceal bleeding by somatostatin: a double-blind, randomized, cross-over study. Gastroenterology 1983;84:100.

15 Raptis S, Zoupas C. Somatostatin not helpful in bleeding esophageal varices. Engl $f$ Med 1979;300:736-7.

16 Jenkins SA, Devitt $P$, Shields $R$. The effect of somatostatin on hepatic haemodynamics in the cirrhotic rat. Langenbecks Arch Chir 1982;357:117-8.

17 Bosch J, Kravetz D, Rodés J. Effects of somatostatin on hepatic and systemic haemodynamics in patients with cirrhosis of the liver and in normal subjects. Gastroenterology 1981;80:526-32.

18 Konturek SJ, Tasler J, Cieszkowski M, et al. Effect of growth hormone releasenhibiting hormone on gastric secretion, mucosal blood flow, and serum gastrin. Gastroenterology 1976;70:737-41.

19 Sonnenberg GE, Keller V, Ferruchoud A, et al. Effect of somatostatin on planchnic haemodynamics in patients with cirrhosis of the liver: comparison 然 $1981 ; 80: 518-25$

20 Parbhoo $S$. The management of bleeding in liver disease. Br 7 Hosp Med 1975; $15: 17-28$.

21 Kayasseh L, Gyr K, Keller V, et al. Somatostatin and cimetidine in peptic-ulcer haemorrhage. Lancet 1980 ; i:844-6.

22 Bringer J, Dubois A, Richard JL, et al. Effets de la somatostatine dans les hemorragies oesophagiennes. Une observation d'oesophagite ulcerce. Nouv Presse Med 1980;17:1225-7.

23 Bosch J, Kravetz D, Terres J, et al. A controlled comparison of continuous

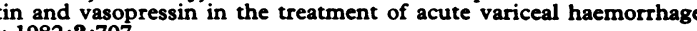
Hepatology 1982;2:707.

(Accepted 23 October 1984)

$\underline{\underline{\underline{T}}}$

\title{
Height at diagnosis of diabetes in children: a study in identical twins
}

\author{
P J HOSKINS, R D G LESLIE, D A PYKE
}

\begin{abstract}
The height at diagnosis of 16 insulin dependent diabetics aged under 19 was compared with that of their unaffected identical cotwins measured at the same time. In eight pairs the diabetic was shorter, and in the remainder the cotwins were the same height. In those diabetics who were shorter than their cotwins at diagnosis the average period of growth delay before diagnosis was at least 35 weeks; by contrast, the mean duration of symptoms was only six weeks. No cause for the growth delay other than the diabetes was known in any of the twins.

These findings show that the onset of insulin dependent diabetes may be a slow process, with growth delay occurring several months before symptoms appear.
\end{abstract}

\section{Introduction}

Growth is a sensitive indicator of health in childhood. Uncontrolled diabetes retards growth: before the discovery of insulin growth stopped completely in children who developed diabetes. ${ }^{1}$ We have used these observations to determine whether diabetes can be present, as shown by growth delay, before the appearance of symptoms.

Studies of heights at diagnosis in diabetic children have produced conflicting results. In most the diabetics were found to be taller than expected, ${ }^{2-9}$ although some studies showed that their heights were normal ${ }^{810} 11$ or that they were shorter. ${ }^{12-14}$ These discrepancies may be due to the difficulty in obtaining exactly matched control groups. When comparing heights the groups must be accurately matched for social class, racial origin, and parental height. The ideal control for a diabetic child is his unaffected identical twin, as twins usually grow at the same rate and to the same final height. ${ }^{15}$

We studied the heights of identical twins discordant for insulin dependent diabetes at the time of diagnosis of the diabetic twin in order (a) to determine whether the diabetic was taller or shorter at diagnosis than his unaffected cotwin and $(b)$, if there was a difference, to estimate how long before diagnosis growth had been affected.

\section{Subjects and methods}

We studied identical twins included in the King's College Hospital survey. Monozygosity was established as described.16
Diabetic Department, King's College Hospital, London SE5 9RS P J HOSKINS, MRCP, MRC research fellow

R D G LESLIE, MD, MRCP, Welloome Trust senior fellow and consultant D A PYKE, MD, FRCP, consultant physician

Correspondence and requests for reprints to: Dr D A Pyke. 